\title{
Murder and Culpable Homicide versus Trauma and Disease: A Case-Based Forensic Pathological Review from the Perspectives of Penal Law in Selected South/South-East Asian Jurisdictions
}

\author{
Kodikara S*, Kumarasinghe G, Rambukwella D, Chandradasa S \\ Department of Forensic Medicine, Faculty of Medicine, University of Peradeniya, Sri Lanka
}

\begin{abstract}
The cause of death was given as acute posterior wall myocardial infarction due to right coronary artery atherosclerosis following a death of a previously healthy, chronic smoker who was found dead following a brief altercation. It was commented that "There were non-fatal, non-grievous injuries and in a setting of acute myocardial infarction and chronic ischemia with fatty metamorphosis, the stress induced by the said altercation could have led to an arrhythmic status causing sudden death". The prima-facie question arising from a trial of such a case is the degree of culpability, namely (1) whether the alleged assailant has caused the death of the deceased? (2) If so, whether he/she qualify for the charge of (2a) culpable homicide not amounting to murder, (2b) culpable homicide amounting to murder or (2c) compete exoneration. This review discusses said vexing questions in a context of the penal law of the said jurisdictions.
\end{abstract}

Keywords: Trauma, Disease, Murder, Culpable homicide, South/South East Asian

Received: 29 May 2021, Revised version accepted: 24 June 2021, Published: 30 June 2021. *Corresponding author: Kodikara S, $\$ email: skodikara@pdn.ac.lk ORCID: https://orcid.org/0000-0002-3790-0489

Cite this article as: Kodikara S, Kumarasinghe G, Rambukwella D, Chandradasa S. Murder and Culpable Homicide versus Trauma and Disease: A Case-Based Forensic Pathological Review from the Perspectives of Penal Law in Selected South/South-East Asian Jurisdictions. Medico-Legal Journal of Sri Lanka. 2021;9(1):33-36.

DOI: http://doi.org/10.4038/mljsl.v9i1.7433

Copyright: @ 2019 with the Medico-legal Journal of Sri Lanka.

This is an open-access article distributed under the terms of the Creative Commons Attribution 4.0 International License, which permits unrestricted use, distribution, and reproduction in any medium provided the original author and source are credited.

\section{Introduction}

Presence of scene, historical and pathological evidence of inflicted trauma and a natural disease simultaneously at autopsy, is a grueling challenge to the forensic pathologist. Two parties; the victim's and the alleged assailant's, enthusiastically await for justice. In the process of administration of justice, three parties; the prosecution, defense and the judge eagerly await for medical expert opinion as a piece of valuable evidence in sorting the alleged crime. A self-analysis of the case by the forensic pathologist in the context of the penal law of the relevant jurisdiction, will be invaluable to face the forthcoming trial; the examination-in-chief, cross examination and reexamination successfully. Also, this will be helpful for a fair administration of justice. This communication highlights such a dilemma analyzed in the context of 'law of murder and homicide' in Bangladesh, India, Malaysia, Singapore and Sri Lanka. A similar analysis is not found in the forensic literature.

\section{Case report}

A 57-year-old previously healthy, chronic smoker was found dead immediately after a brief altercation. The alleged assailant assaulted the deceased using a small club. The autopsy revealed a moderately built person. The summary of injuries he had are as follows.

1. An abrasion of $0.5 \mathrm{~cm} \times 1.5 \mathrm{~cm}$ on the right patella.

2. An abrasion of $2.5 \mathrm{~cm} \times 1 \mathrm{~cm}$ on the right knee joint just above the patella.

3. A contusion of $1 \mathrm{~cm} \times 2 \mathrm{~cm}$ on the left elbow joint medially.

4. A contusion of $11 \mathrm{~cm} \mathrm{x} 7 \mathrm{~cm}$ on the right side of the chest around the right nipple.

5. A contusion of $1 \mathrm{~cm} \times 0.5 \mathrm{~cm}$ on the left mid clavicle.

6. A $3 \mathrm{~mm}$ linear abrasion on the anterior aspect of the neck.

7. A muscular contusion of $2.5 \mathrm{~cm} \times 2 \mathrm{~cm}$ on the left back of the chest over the left scapula. This was not visible to the outside.

8. A muscular contusion of $1 \mathrm{~cm} \times 1.5 \mathrm{~cm}$ on the left back of the chest just medial to the left scapula. This was not visible to the outside.

The heart weight was 300 grams. The right coronary artery had marked stenosis leading to obstruction at its second part by a calcified atheroma. The anterior descending artery had marked stenosis leading to obstruction at its beginning by a calcified atheroma. 
The circumflex artery was completely patent and devoid of atheroma or calcification.

The posterior wall immediately adjacent to the interventricular septum was having multiple patchy fibrosis from the base of the heart, up to the apex (figure 1). The aorta had multiple atherosclerotic patches. Both lungs were congested and edematous with weights of $600 \mathrm{~g}$ (right) and $540 \mathrm{~g}$ (left).

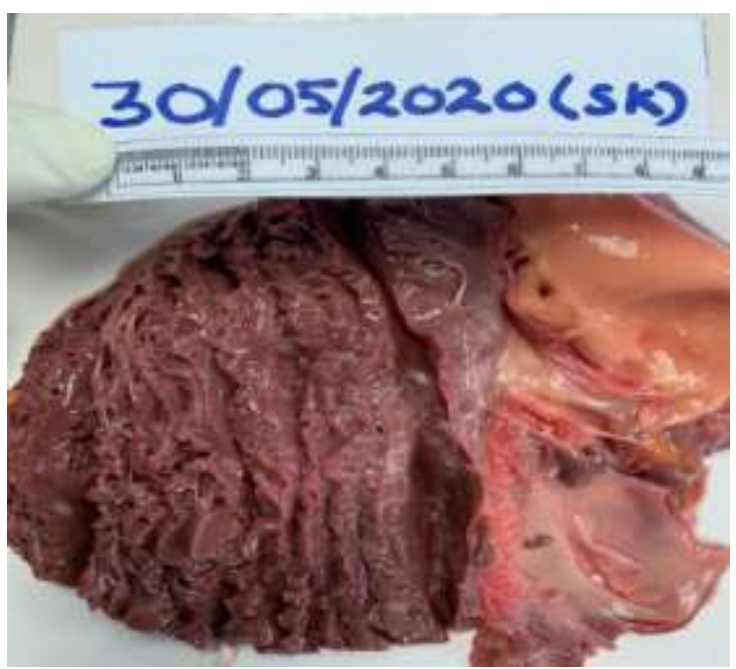

Figure 1. Multiple patchy fibrosis in the posterior wall of the heart.

Histopathologic examination of the heart showed loss of cytoplasmic structure, wavy myocardial fibers (fig. 2), scanty amount of contraction bands, interstitial edema and profuse fibrosis. Within the areas of fibrosis, fatty metamorphosis was present (fig. 3). The right coronary and left anterior descending artery showed marked stenosis leading to obstruction due to atherosclerosis (fig. 4). Widened alveolar spaces, multiple carbon particles, intermittent giant cells, heart failure cells and patchy edema were seen in the lung.

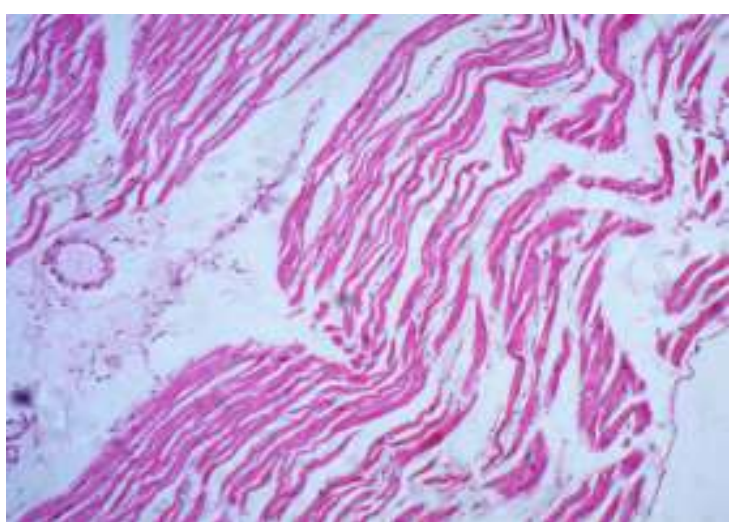

Figure 2. Loss of cytoplasmic structure, absence of contraction bands \& neutrophilic infiltration, and the presence of wavy myocardial fibres in the myocardium. (H \& E X 40)

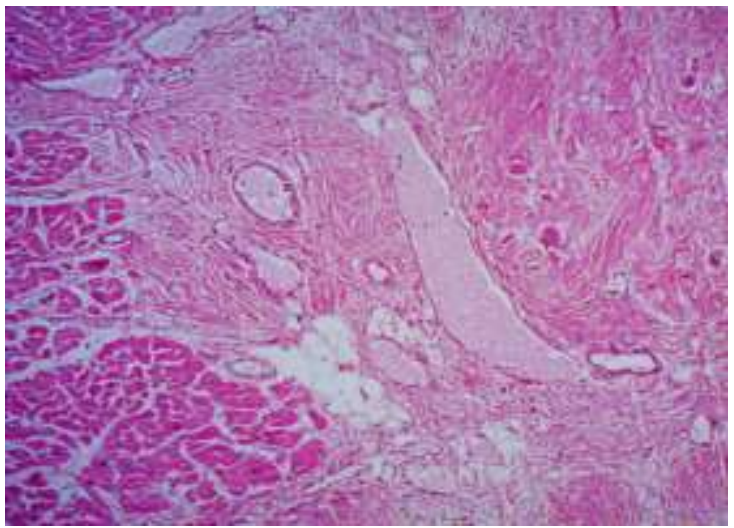

Fig. 3: Fatty metamorphosis in an area of myocardial fibrosis. (H \&E X40)

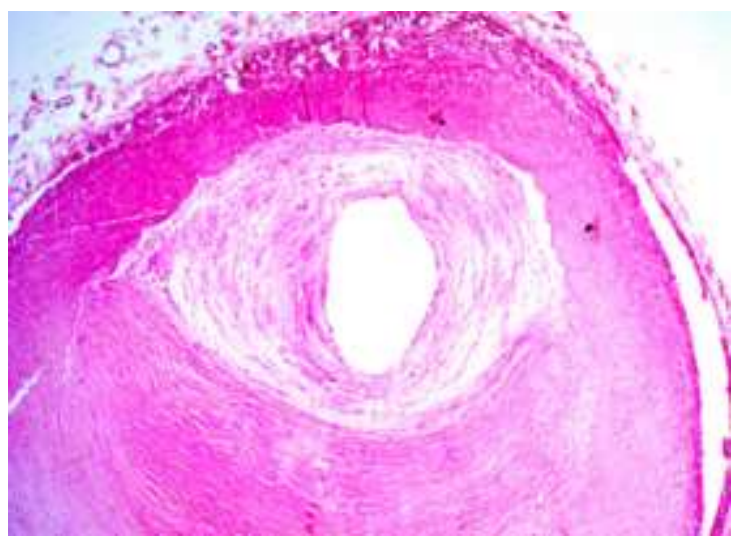

Fig. 4: The right coronary artery obstructed with an atherosclerotic plaque. (H \&E X40)

Therefore the possible/likely cause of death was acute posterior wall myocardial infarction due to right coronary artery atherosclerosis. The contributory cause of death was chronic ischemic heart disease.

As a 'comment' followed by the cause of death statement, it was stated that "In a setting of acute myocardial infarction and chronic ischemia with fatty metamorphosis, the stress induced by the said altercation could have led to an arrhythmic status causing sudden death.

\section{Discussion}

Microscopic changes in the myocardium are not obvious when an infarction is $0-4$ hours old.[1, 2] Appearance of wavy fibers with the beginning of contraction band myonecrosis happens in a 4-6 hours old infarction.[1, 2] Appearance of substantial amount of contraction bands and nascent neutrophilic infiltrate indicate the infarction is 12-24 hours old. In the present case, appearance of hyperesoinophilic wavy myocardial fibers with scanty amount of contraction bands and absence of nascent neutrophilic infiltrate in the posterior wall support that there was a possible acute myocardial infarction and was 4-12 hours old. The macroscopic and microscopic findings of the obstruction of right 
coronary artery by a calcified atheroma supports that the antecedent cause of death or the reason for posterior wall myocardial infarction was right coronary artery atherosclerosis.

An acute myocardial infarction of 4-12 hours old is arrhythmogenic. In addition, a patch of myocardial fibrosis could lead to arrhythmia. One of the late responses of the heart to ischemic injury is the conversion of muscles into adipose, sometimes referred as fatty metamorphosis. Such change is essentially a scar composed of fat and can be arrhythmogenic.[2] All such changes were seen in this case, making the victim vulnerable for a fatal cardiac arrhythmia.

The deceased died quickly leading to sudden stoppage of cardiac function and this could occur in a setting of a cardiac arrhythmia. Therefore, it is reasonable to believe that the most likely mechanism of death in this case was cardiac arrhythmia.

The circumstance of the death in this case, as depicted by the cause of death statement per se, is purely natural. However, given the fact that the victim died during a witnessed altercation, a 'natural' circumstance is contradictory from clinicopathological perspectives. Therefore, a summary statement was given correlating the natural disease condition to the traumatic incident.

Acceleration of death of a person, who suffers from a disease, by causing non-fatal bodily injuries, is a dilemma of a forensic pathologist. This concept is included in the penal law of many jurisdictions. Bangladesh, India, Malaysia, Singapore and Sri Lanka, are such four jurisdictions. The penal law of Bangladesh, Malaysia Singapore and Sri Lanka, are based on the Indian penal law which originated from the English law. Because of this common source of origination, the law of murder and homicide in the said four jurisdictions are almost same.[3-8]

To constitute the crime of murder, two elements are needed; namely the actus reus and mensrea.[8] Actus reus is the illegal action taken by the alleged assailant. The mensrea is the mental element simply understood either as intention or knowledge to kill the victim.

The explanation 1 given under the offence of 'culpable homicide' in the said jurisdictions elaborates the legal repercussion of accelerating the death of a diseased person by trauma as follows. "A person, who causes bodily injury to another who is labouring under a disorder, disease, or bodily infirmity, and thereby accelerates the death of that other, shall be deemed to have caused his death". Accordingly, the alleged assailant, in this case, has caused the death of the victim.
Penal law of the said four countries recognizes four circumstances where culpable homicide becomes murder as follows:

Firstly-If the act by which the death is caused is done with the intention of causing death; or

Secondly-If it is done with the intention of causing such bodily injury as the offender knows to be likely to cause the death of the person to whom the harm is caused; or

Thirdly-If it is done with the intention of causing bodily injury to any person, and the bodily injury intended to be inflicted is sufficient in the ordinary course of nature to cause death; or

Fourthly-If the person committing the act knows that it is so imminently dangerous that it must in all probability cause death or such bodily injury as is likely to cause death, and commits such act without any excuse for incurring the risk of causing death or such injury as aforesaid.

The actus reus in the present case was the infliction of blunt force. Was the actus reus sufficient to cause the death here? From a forensic pathological perspective, the inflicted physical injuries per se were neither sufficient directly to cause the death nor fatal in the ordinary course of nature with regard to a person in a sound state of health care. Also, the said injuries were not imminently dangerous that it must in all probability cause death, or are likely to cause death.

Did the alleged assailant have the sufficient degree of mensrea to kill the victim? Such grave intention or knowledge stipulated by above four circumstances in order to convict for the offence of murder, cannot be drawn from the inflicted injuries per se. The inflicted injuries are non-grievous as per the penal law of given jurisdictions. Therefore, it is reasonable to arrive at the conclusion that the alleged assailant intended only to inflict non-grievous hurt. Therefore, the answer to the above question is 'no'.

Thus, the alleged assailant had no 'intention' to cause the death of the victim according to the first circumstance mentioned above. The bodily injuries inflicted were insufficient to cause the death in the ordinary course of nature. Therefore, the level of 'intention' of causing bodily injuries as mentioned in the third circumstance can also be excluded. The severe degree of 'knowledge' stipulated by the fourth circumstance can also be excluded because of the fact that the injuries were non-grievous in nature.

Differentiation of the culpability as to 'culpable homicide' or 'murder' in case of a death of a person 
suffering from a disease condition, following infliction of trauma is illustrated as follows in the said penal codes.

"A knowing that $\mathrm{Z}$ is labouring under such a disease that a blow is likely to cause his death, strikes him with the intention of causing bodily injury. $Z$ dies in consequence of the blow. A is guilty of murder, although the blow might not have been sufficient in the ordinary course of nature to cause the death of a person in a sound state of health. But if $\mathrm{A}$, not knowing that $\mathrm{Z}$ is labouring under any disease, gives him such a blow as would not in the ordinary course of nature kill a person in sound state of health here $\mathrm{A}$, although he may intend to cause bodily injury, is not guilty of murder, if he did not intend to cause death, or such bodily injury as in the ordinary course of nature would cause death".

In the present case, there was no significant past medical history known by the victim or the next of kin. The existed disease condition had never been diagnosed clinically and for the first time, it was diagnosed at the autopsy and subsequent histopathological examination of the deceased. Therefore, it is reasonable to hypothesize that the alleged assailant did not know that the victim was laboring under a myocardial pathology at the time of altercation. Hence, although the alleged assailant intended to cause non-grievous bodily injuries, he did not intend to cause death or such bodily injury that would be sufficient to cause the death in the ordinary course of nature. However, possibly, the stress caused during the course of action of actus reus could have induced cardiac arrhythmia causing death.

\section{Conclusions}

In summary, according to the 'explanation 1', the alleged assailant has caused the death of the victim. However, in accordance with the second circumstance read with the illustration in the 'law of murder', the alleged assailant has not caused the offence of 'murder'. Instead the alleged assailant may have caused the offence of 'culpable homicide not amounting to murder'.

As the law of hurt and grievous hurt are almost same in the said jurisdictions [2-6] this also highlights the important role of the forensic pathologist in indicating the category of hurt (whether it is simple hurt, grievous hurt, endangering life, fatal in the ordinary course of nature or necessarily fatal) of inflicted injuries in the post mortem report. This helps the judiciary to draw the degree of actus reus and mens rea of an alleged assailant.

\section{Disclosure statement}

Conflict of interest: The authors declare that there is no conflict of interest.

\section{Funding: None}

\section{References}

1. Visonà SD, Benati $\mathrm{D}$, Monti $\mathrm{MC}$, et al. Diagnosis of sudden cardiac death due to early myocardial ischemia: An ultrastructural and immunohistochemical study. Eur J Histochem. 2018; 62 (2): 2866. doi:10.4081/ejh.2018.2866

2. Cummings PM, Trelka DP, Springer KM, Atlas of Forensic Histopathology, Cambridge University Press, Cambridge, 2011.

3. Penal Code of Bangladesh, Act No. XLV of 1860.

4. Indian Penal Code, Act No. 45 of 1860.

5. Penal Code of Malaysia, Act No. 574 of 1936.

6. Penal Code of Singapore, Ordinance No. 4 of 1871.

7. Penal Code of Sri Lanka, Ordinance No. 2 of 1883.

8. Gour HS. The Penal Law of India, eleventh ed., Law Publishers, India, 2009. 